\title{
Six months versus 12 months dual antiplatelet therapy after drug-eluting stent implantation in ST-elevation myocardial infarction (DAPT-STEMI): randomised, multicentre, non-inferiority trial
}

\author{
Elvin Kedhi, ${ }^{1}$ Enrico Fabris, ${ }^{1,2}$ Martin van der Ent, ${ }^{3}$ Pawel Buszman, ${ }^{4,5}$ Clemens von Birgelen, ${ }^{6,7}$ \\ Vincent Roolvink, ${ }^{1}$ Alexander Zurakowski, ${ }^{8}$ Carl E Schotborgh, ${ }^{9}$ Jan C A Hoorntje, ${ }^{10}$ \\ Christian Hasbø Eek, ${ }^{11}$ Stéphane Cook, ${ }^{12}$ Marco Togni, ${ }^{12}$ Martijn Meuwissen, ${ }^{13}$ \\ Niels van Royen, ${ }^{14}$ Ria van Vliet, ${ }^{3}$ Hans Wedel, ${ }^{15}$ Ronak Delewi, ${ }^{16}$ Felix Zijlstra ${ }^{6}$
}

\begin{abstract}
For numbered affiliations see end of article.

Correspondence to: E Kedhi e.kedhi@isala.nl

Additional material is published online only. To view please visit the journal online.

Cite this as: $B M J$ 2018;363:k3793 http://dx.doi.org/10.1136/bmj.k3793

Accepted: 22 August 2018
\end{abstract}

\section{ABSTRACT}

OBJECTIVE

To show that limiting dual antiplatelet therapy (DAPT) to six months in patients with event-free ST-elevation myocardial infarction (STEMI) results in a non-inferior clinical outcome versus DAPT for 12 months.

\section{DESIGN}

Prospective, randomised, multicentre, non-inferiority trial.

\section{SETTING}

Patients with STEMI treated with primary percutaneous coronary intervention $(\mathrm{PCl})$ and second generation zotarolimus-eluting stent.

\section{PARTICIPANTS}

Patients with STEMI aged 18 to 85 that underwent a primary $\mathrm{PCl}$ with the implantation of second generation drug-eluting stents were enrolled in the trial. Patients that were event-free at six months after primary $\mathrm{PCl}$ were randomised at this time point.

\section{INTERVENTIONS}

Patients that were taking DAPT and were eventfree at six months were randomised 1:1 to single antiplatelet therapy (SAPT) (ie, aspirin only) or to DAPT for an additional six months. All patients that were randomised were then followed for another 18 months (ie, 24 months after the primary $\mathrm{PCl}$ ).

MAIN OUTCOME MEASURES

The primary endpoint was a composite of all cause mortality, any myocardial infarction, any revascularisation, stroke, and thrombolysis in

\section{WHAT IS ALREADY KNOWN ON THIS TOPIC}

The optimal duration of dual antiplatelet therapy (DAPT) after percutaneous coronary intervention $(\mathrm{PCl})$ with second generation drug-eluting stents is unclear No other trial has evaluated the safety of DAPT for less than 12 months in patients with ST-elevation myocardial infarction (STEMI), treated with second generation drug-eluting stents

\section{WHAT THIS STUDY ADDS}

A dedicated randomised clinical trial to compare six versus 12 months of DAPT after primary $\mathrm{PCI}$ for patients with STEMI

Limiting DAPT duration to six months in patients with STEMI that are event-free results in a non-inferior clinical outcome, as assessed by a patient-oriented composite clinical endpoint versus 12 months of DAPT

If clinically mandated, a shorter DAPT is safe for patients with STEMI

myocardial infarction major bleeding at 18 months after randomisation.

RESULTS

A total of 1100 patients were enrolled in the trial between 19 December 2011 and 30 June 2015. 870 were randomised: 432 to SAPT versus 438 to DAPT. The primary endpoint occurred in $4.8 \%$ of patients receiving SAPT versus $6.6 \%$ of patients receiving DAPT (hazard ratio $0.73,95 \%$ confidence interval 0.41 to 1.27, $P=0.26)$. Non-inferiority was met $(P=0.004$ for non-inferiority), as the upper $95 \%$ confidence interval of 1.27 was smaller than the prespecified noninferiority margin of 1.66 .

\section{CONCLUSIONS}

DAPT to six months was non-inferior to DAPT for 12 months in patients with event-free STEMI at six months after primary $\mathrm{PCl}$ with second generation drug-eluting stents.

TRIAL REGISTRATION

Clinicaltrials.gov NCT01459627.

\section{Introduction}

Dual antiplatelet therapy (DAPT) after percutaneous coronary intervention (PCI) has been used primarily to avoid abrupt thrombotic closure of the vessel after stent implantation. ${ }^{1}$ The recommended duration of DAPT has been changed in the last decades, particularly after introduction of the first generation drug-eluting stents. ${ }^{2}$ The observed high rates of stent thrombosis with these devices motivated the interventional community to extend DAPT to 12 months, ${ }^{3}$ although there was a lack of evidence for this approach. The introduction of second generation drug-eluting stents has drastically reduced the risk of stent thrombosis compared with first generation and bare metal stents. ${ }^{4-6}$ Different trials and meta-analyses have shown that shorter DAPT regimens after PCI with second generation drug-eluting stents are equally safe; however, the optimal duration of DAPT remains a matter of debate. ${ }^{5-9}$ Current international guidelines recommend at least six months of DAPT after PCI for stable ischaemic coronary disease and 12 months in the setting of acute myocardial infarction. ${ }^{10} 11$ For acute coronary syndromes this recommendation is derived from two randomised trials. ${ }^{1213}$ However, the observed benefit was noted only in the first months and may have been biased by the positive influence of upstream preloading with DAPT. 
DAPT reduces the risk of thromboembolic events in general, but it is also associated with a higher risk of major bleeding that can sometimes be fatal. ${ }^{14}$ The risk of bleeding is unique to each patient and is not always known before PCI, particularly before primary $\mathrm{PCI}$ in the setting of a ST-elevation myocardial infarction (STEMI). So far, no trial has shown that extending DAPT from six to 12 months after primary PCI for STEMI is associated with a meaningful improvement of stent thrombosis and other safety outcomes such as myocardial infarction, stroke, or death. As the safety and efficacy profiles of second generation drug-eluting stents are superior to those of first generation drugeluting stents and bare metal stents, and considering the unknown risk of bleeding before primary PCI, it may be appealing to consider a shorter DAPT for patients with STEMI treated with second generation drug-eluting stents.

Therefore, we performed a prospective, randomised trial of six versus 12 months of DAPT after second generation drug-eluting stent implantation in patients presenting with STEMI (DAPT-STEMI trial) to evaluate whether six months of DAPT is non-inferior to 12 months of DAPT, in patients that are event-free at six months follow-up after primary PCI.

\section{Methods}

\section{Study design}

The DAPT-STEMI trial is a prospective, randomised, multicentred, open label, non-inferiority trial designed to compare the clinical outcomes of six versus 12 months of duration of dual antiplatelet therapy (DAPT) in patients with ST-elevation myocardial infarction (STEMI) that underwent primary percutaneous coronary intervention (PCI) with second generation drug-eluting stents. The trial was conducted at 17 study sites in the Netherlands, Norway, Poland, and Switzerland. The study design has been reported..$^{15}$ The trial was conducted in compliance with the International Conference on Harmonisation and the Declaration of Helsinki. The institutional review board of each participating institution approved the study. All the patients provided written informed consent.

Data were reviewed regularly throughout the trial by an independent data and safety monitoring committee. An independent academic clinical-events committee (Diagram BV), whose members were unaware of the group assignments, adjudicated all endpoints using standard definitions (see supplementary materials, endpoint definitions). An independent, blinded core laboratory judged revascularisation and stent thrombosis endpoints. DAPT-STEMI is an investigator driven trial.

\section{Participant selection}

The trial population consisted of patients with STEMI aged 18 to 85 who underwent a primary PCI with the implantation of second generation drug-eluting stents. Patients that fulfilled the inclusion and exclusion criteria (see supplementary materials, table e1) were enrolled after the primary PCI procedure. All patients were followed during the first six months. Patients that were event-free at six months followup who fulfilled the randomisation criteria were at this time point randomised to either stop or continue DAPT for an additional six months. All patients that were randomised were then followed for another 18 months (ie, 24 months after the primary PCI) (see supplementary materials, figure e1).

\section{Interventions}

All patients with STEMI were treated according to standard clinical practice. The choice of the vascular access route (ie, radial $v$ femoral) was left to the discretion of the operator, although radial approach was strongly recommended to avoid bleeding complications at the puncture site. Thrombus aspiration and lesion predilatation were left to the discretion of the operator. The stent device used was the Resolute Integrity second generation zotarolimus-eluting stent (Medtronic, Santa Rosa, CA).

In accordance with international revascularisation guidelines, ${ }^{10} 11$ the DAPT consisted of aspirin loading dose of $150-300 \mathrm{mg}$ orally or $250-500 \mathrm{mg}$ intravenously followed by $75-100 \mathrm{mg}$ orally daily. The P2Y12 inhibitors were prasugrel, ticagrelor, or clopidogrel. The initial dose for prasugrel was $60 \mathrm{mg}$ orally followed by $10 \mathrm{mg}$ orally daily. Patients aged 75 years and over and with a body weight of less than $60 \mathrm{~kg}$ were treated with an initial dose of $60 \mathrm{mg}$ prasugrel orally followed by $5 \mathrm{mg}$ prasugrel orally daily. The initial dose of ticagrelor was $180 \mathrm{mg}$ orally followed by $90 \mathrm{mg}$ orally twice daily. The initial dose for clopidogrel was $600 \mathrm{mg}$ orally followed by $75 \mathrm{mg}$ orally daily. After six months, patients who fulfilled the inclusion and exclusion criteria were randomised, to either discontinue DAPT (ie, aspirin only) or continue DAPT for another six months after randomisation (ie, until 12 months after primary PCI) (see supplementary materials, figure e1). In all patients, $80-100 \mathrm{mg}$ aspirin daily was continued indefinitely.

If required, additional (scheduled) staged revascularisations in non-culprit lesions were performed within 45 days from the primary PCI. However, even in these cases, the time of six months follow-up was based on the date of the initial (primary) PCI. All patients that were randomised were followed for 18 months after randomisation (ie, 24 months after primary $\mathrm{PCI}$ ).

\section{Outcome measures}

The primary endpoint of this trial is a patientoriented composite endpoint of all cause mortality, any myocardial infarction, any revascularization, stroke, or thrombolysis in myocardial infarction major bleeding at 18 months follow-up after randomisation (ie, 24 months after primary PCI). The major secondary endpoint was a composite of all cause mortality, any myocardial infarction, stent thrombosis, stroke, and thrombolysis in myocardial infarction major bleeding at 18 months follow-up after randomisation. Additional clinical endpoints were the individual components of the primary endpoint. Trial endpoint definitions 
are provided in the supplementary materials. For the purpose of the primary endpoint, myocardial infarction was adjudicated based on the Academic Research Consortium definitions. ${ }^{16}$ Stroke was defined as any acute neurological event with a duration of at least 24 hours, with focal signs and symptoms and without evidence supporting any alternative explanation, and confirmed by imaging by computed tomography or magnetic resonance imaging, or by pathological evidence. Bleeding was evaluated based on the thrombolysis in myocardial infarction bleeding classification. ${ }^{17}$

\section{Sample size and statistical analyses}

The trial was designed to test the hypothesis that single antiplatelet therapy (SAPT) with aspirin after six months in patients with STEMI that were eventfree would be non-inferior to DAPT with respect to the primary endpoint. We estimated the hazard ratio of the primary endpoint in the treatment and control groups using a Cox proportional-hazards model. A pre-defined non-inferiority margin of 1.66 was used in this trial. Non-inferiority of SAPT versus DAPT will be concluded if the estimated 95\% confidence interval of the hazard ratio lies entirely below this margin. If the upper limit of the 95\% confidence interval exceeds this margin we do not reject the null hypothesis of inferiority. The non-inferiority margin chosen in our trial, reflects the knowledge from other trials within cardiology that

\section{Patients enrolled who had STEMI ( $\mathrm{n}=1100)$}

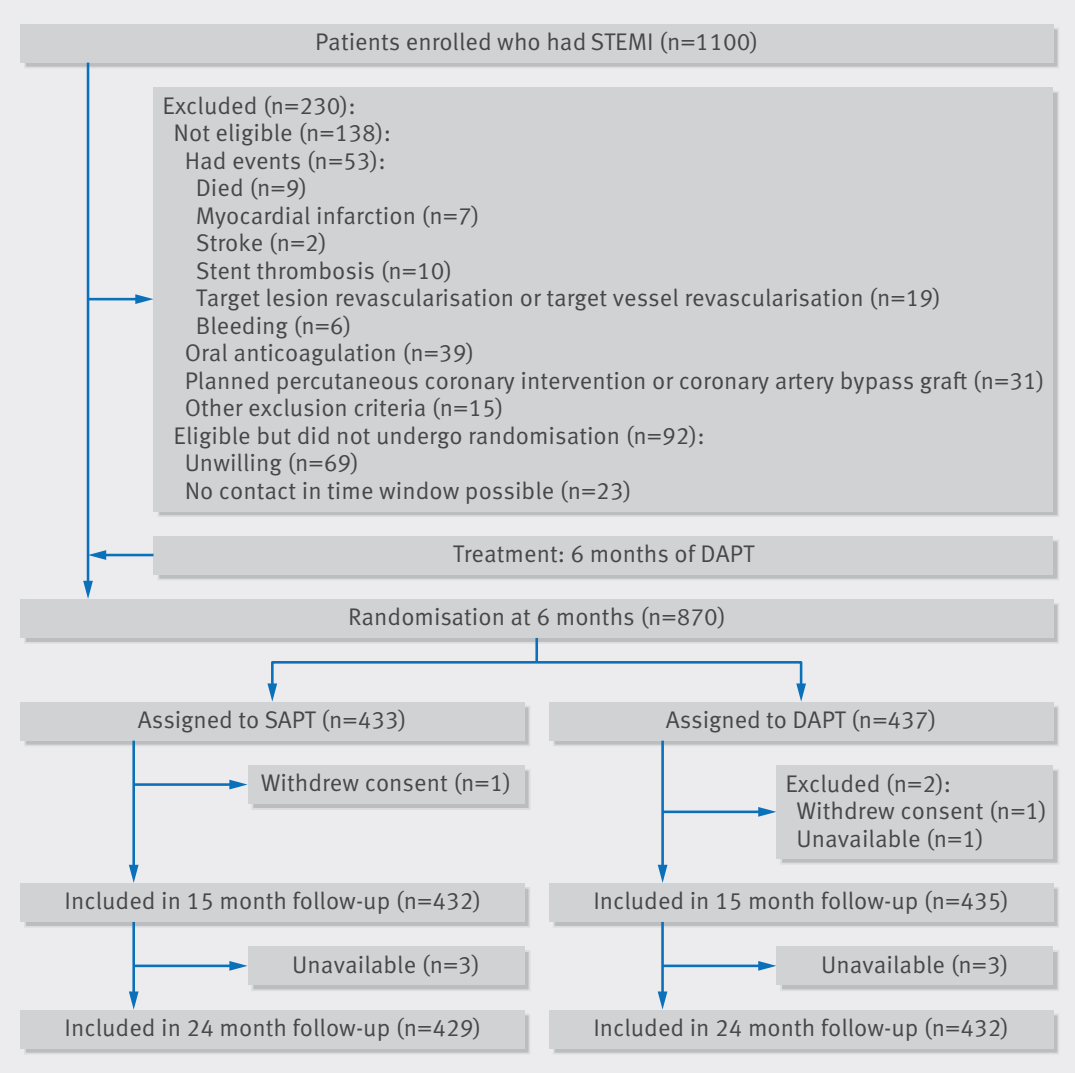

Fig 1 | Study flow diagram were available in the literature when this trial was designed. ${ }^{18-21}$

The sample size was calculated under the assumption that the $\alpha$ value was 0.05 for a two sided test ( 0.025 for a one sided test) with a power of $85 \%$. The endpoint at 18 months after randomisation was assumed to be $15 \%$. Taking into account the patients that were ineligible for randomisation owing to clinical events in the first six months or other exclusion criteria, a total sample size of 1100 patients was required.

The primary analysis, which was performed on an intention to treat basis, included all patients that underwent randomisation, regardless of whether they received treatment. The results for the primary endpoint are presented as time to event curves (Kaplan-Meier). We based the $\mathrm{P}$ values comparing the clinical outcomes in the treatment groups on logrank tests. We calculated hazard ratios and corresponding 95\% confidence intervals using Cox proportional hazards models. We calculated the P value for noninferiority by testing the estimated hazard ratio against the non-inferiority hazard ratio of 1.66 . We assumed an approximate posterior distribution for the treatment effect based on the estimated hazard ratio and its standard error. We used this to derive the probability that the true hazard ratio is over 1.66. All tests were two tailed and conducted at a significance level of 0.05. Data for patients that did not have an endpoint event were censored for the analysis of that endpoint at the time of the last known contact or at 18 months (ie, 24 months after the primary PCI), whichever was earlier. For descriptive purposes, a sensitivity analysis on a per protocol basis for the primary endpoint was performed. Analysis were performed with IBM statistical package for social sciences (SPSS) version 24 and SAS version 9.4 (SAS Institute, Cary, $\mathrm{NC}$ ).

\section{Patient and public involvement}

No patients were involved in setting the research question or the outcome measures, nor were they involved in developing plans for design or implementation of the study. The ethical committee had a patient representative member. No patients were asked to advise on interpretation or writing up of results. There are no plans to disseminate the results of the research to study participants or the relevant patient community.

\section{Results}

\section{Patient characteristics}

Between 19 December 2011 and 30 June 2015, a total of 1100 patients were enrolled in the trial. Figure 1 shows that $230(20.9 \%)$ of these patients were not randomised after six months of follow-up. Of the 230 patients that were excluded, 138 were not eligible for randomisation: 55 patients had events during the first six months and 83 did not fulfil the other randomisation criteria. A total of 92 patients were eligible but were not randomised. Among those who were eligible but did 


\begin{tabular}{|c|c|c|}
\hline Characteristic & SAPT $(n=433)$ & DAPT $(n=437)$ \\
\hline \multicolumn{3}{|l|}{ Patient characteristic } \\
\hline Age (years) & $59.8 \pm 10.7$ & $60.2 \pm 10.3$ \\
\hline Male & $337(78 \%)$ & $332(76 \%)$ \\
\hline Body mass index & $27.8 \pm 4.3$ & $27.9 \pm 4.5$ \\
\hline \multicolumn{3}{|l|}{ Medical history } \\
\hline Previous coronary artery bypass graft & $8(2 \%)$ & $2(0.5 \%)$ \\
\hline Previous percutaneous coronary intervention & $29(7 \%)$ & $18(4 \%)$ \\
\hline Previous myocardial infarction & $26(6 \%)$ & $20 / 436(5 \%)$ \\
\hline Stroke or transient ischaemic attack & $14(3 \%)$ & $8 / 436(2 \%)$ \\
\hline Peripheral arterial disease & $16(4 \%)$ & $9 / 436(2 \%)$ \\
\hline Congestive heart failure & $16(4 \%)$ & 19/436 (4\%) \\
\hline \multicolumn{3}{|l|}{ Risk factors } \\
\hline Diabetes mellitus & $54(13 \%)$ & $61(14 \%)$ \\
\hline Hypertension & $193(45 \%)$ & $195 / 436(45 \%)$ \\
\hline Dyslipidaemia & $120(28 \%)$ & $125 / 436(29 \%)$ \\
\hline Current smoker & $218 / 431(51 \%)$ & $205(47 \%)$ \\
\hline Family history of coronary artery disease & $143 / 431(33 \%)$ & $144 / 436(33 \%)$ \\
\hline \multicolumn{3}{|l|}{ Drugs at start of study } \\
\hline \multicolumn{3}{|l|}{ P2Y12 inhibitors: } \\
\hline Clopidogrel & $180(42 \%)$ & $182(42 \%)$ \\
\hline Prasugrel & $128(29 \%)$ & $132(30 \%)$ \\
\hline Ticagrelor & $125(29 \%)$ & $123(28 \%)$ \\
\hline \multicolumn{3}{|l|}{ Percutaneous coronary intervention } \\
\hline \multicolumn{3}{|l|}{ Thrombolysis in myocardial infarction flow: } \\
\hline Baseline «3 & $355 / 432(82 \%)$ & $355(81 \%)$ \\
\hline After $\mathrm{PCl} 3$ & $411(95 \%)$ & $421 / 436(97 \%)$ \\
\hline \multicolumn{3}{|l|}{ Infarct related artery: } \\
\hline Left anterior descending & $169(39 \%)^{*}$ & $188(43 \%)$ \\
\hline Right coronary artery & $175(41 \%)$ & $179(41 \%)$ \\
\hline Right circumflex artery & $89(21 \%)$ & $70(16 \%)$ \\
\hline \multicolumn{3}{|l|}{ Lesion type culprit: } \\
\hline B2 & $158 / 428(37 \%)$ & $158 / 433(36 \%)$ \\
\hline C & $108 / 428(25 \%)$ & $101 / 433(24 \%)$ \\
\hline \multicolumn{3}{|l|}{ Stent type culpritt: } \\
\hline Zotarolimus-eluting stent & $400 / 432(93 \%)$ & $407 / 436(93 \%)$ \\
\hline Other & $32 / 432(7 \%)$ & $29 / 436(7 \%)$ \\
\hline \multicolumn{3}{|l|}{ Index procedure: } \\
\hline Treated lesions & $1.09 \pm 0.3$ & $1.10 \pm 0.3$ \\
\hline Treated vessels & $1.08 \pm 0.3$ & $1.07 \pm 0.3$ \\
\hline Stents & $1.42 \pm 0.8$ & $1.48 \pm 0.8$ \\
\hline Total stent length $(\mathrm{mm})$ & $28.5 \pm 16$ & $29.8 \pm 16$ \\
\hline \multicolumn{3}{|l|}{ Minimum stent diameter $(\mathrm{mm}) \neq$ : } \\
\hline$<3$ & $189 / 613(31 \%)$ & $178 / 645(28 \%)$ \\
\hline$\geq 3$ & $424 / 613(69 \%)$ & $467 / 645(73 \%)$ \\
\hline Non-culprit lesion intervention & $54(12.5 \%)$ & $62(14 \%)$ \\
\hline
\end{tabular}

not undergo randomisation, the most common reason was withdrawal of consent during the six months between enrolment and randomisation (69 patients). A total of 870 patients were randomised.

Complete information on the primary endpoint was obtained for $99 \%(861 / 870)$ of the randomised patient population. Figure 1 shows that at 15 months follow-up, one patient was lost and two patients withdrew consent. For the final 18 months follow-up (ie, 24 months after the primary PCI), six patients were unavailable, but were known to be alive.

Table 1 shows that the two treatment groups were well balanced with respect to baseline characteristics. On average, patients were 60 years old and $76.9 \%$ of them were male.
In the DAPT arm of the trial, six patients received DAPT for fewer than 12 months; two because of bleeding events and four because of poor compliance. In the SAPT arm of the trial, 14 patients received DAPT for more than six months; four took SAPT with P2Y12 inhibitor and 10 continued DAPT without evident reason. These crossovers were based on the patient's or doctor's preference. None of these patients had major cardiac adverse events.

\section{Primary endpoint}

During the 18 months after randomisation (ie, 24 months after the primary $\mathrm{PCI}$ ), the primary endpoint, a composite of all cause mortality, any myocardial infarction, any revascularization, stroke, or thrombolysis in myocardial infarction major bleeding occurred in $4.8 \%$ in the SAPT group versus $6.6 \%$ in the DAPT group (hazard ratio SAPT $v$ DAPT 0.73 , $95 \%$ confidence interval 0.41 to $1.27 ; \mathrm{P}=0.26$ ). Noninferiority was met $(\mathrm{P}=0.004$ for non-inferiority), as the upper $95 \%$ confidence interval of 1.27 is smaller than the prespecified non-inferiority margin of 1.66 (see table 2 and fig 2).

The per protocol analysis of the primary endpoint confirmed the result of the main (intention to treat) analysis, (hazard ratio 0.74 , 95\% confidence interval 0.42 to $1.30 ; \mathrm{P}=0.005$ for non-inferiority).

The hazard ratio proportionality assumption was examined by graphical checks (see supplementary materials, fig e2) and by applying supremum tests (see supplementary materials, fig e3) using the assess statement in Proc PHREG in SAS. Non-inferiority of SAPT versus DAPT was calculated across different thresholds of the hazard ratio. Table 3 shows that the trial could prove the non-inferiority not only for the chosen non-inferiority margin of 1.66 but for any hazard ratio margin above 1.2.

\section{Secondary endpoints}

The major secondary endpoint, a composite of safety and bleeding at 18 months (ie, 24 months after the primary PCI), occurred in $3.2 \%$ in the SAPT group versus $4.3 \%$ in the DAPT group (hazard ratio 0.75 , $95 \%$ confidence interval 0.37 to $1.49 ; \mathrm{P}=0.40$ ). Between the two treatment groups, there was no statistically significant difference in the incidence of all cause mortality $(0.7 \% \vee 1.4 \%$, hazard ratio 0.51 , $95 \%$ confidence interval 0.13 to $2.02 ; \mathrm{P}=0.33)$; death from cardiac causes $(0.5 \% v 0.9 \%, 0.51,0.09$ to 2.76 ; $\mathrm{P}=0.43)$; any myocardial infarction $(1.8 \% \vee 1.8 \%$, $1.02,0.38$ to $2.71 ; \mathrm{P}=0.97)$; stent thrombosis $(0.7 \%$ $v$ 0.9\%, 0.76, 0.17 to 3.39; $\mathrm{P}=0.72)$; stroke $(0.7 \% v$ $0.7 \%, 1.02,0.21$ to $5.03 ; \mathrm{P}=0.99)$; and thrombolysis in myocardial infarction major bleeding $(0.2 \% v 0.5 \%$, $0.51,0.05$ to $5.57 ; \mathrm{P}=0.58$ ) (see table 2 ).

\section{Discussion}

\section{Principal findings}

This study is the first dedicated randomised clinical trial to compare six versus 12 months of 


\begin{tabular}{|c|c|c|c|c|}
\hline Outcome & SAPT $(n=433)$ & DAPT $(n=437)$ & $\begin{array}{l}\text { Hazard ratio SAPT } v \text { DAPT } \\
(95 \% \mathrm{Cl})\end{array}$ & P value \\
\hline \multicolumn{5}{|l|}{ Primary endpoint } \\
\hline Composite* $^{\star}$ & $21(4.8 \%)$ & $29(6.6 \%)$ & $0.73(0.41$ to 1.27$)$ & $\begin{array}{l}0.26 \\
0.004 \text { for } \\
\text { non-inferiority }\end{array}$ \\
\hline \multicolumn{5}{|l|}{ Secondary endpoints } \\
\hline Compositet & $14(3.2 \%)$ & $19(4.3 \%)$ & 0.75 (0.37 to 1.49$)$ & 0.40 \\
\hline Death: & $3(0.7 \%)$ & $6(1.4 \%)$ & 0.51 (0.13 to 2.02$)$ & 0.33 \\
\hline Cardiac & $2(0.5 \%)$ & $4(0.9 \%)$ & 0.51 (0.09 to 2.76$)$ & 0.43 \\
\hline Myocardial infarction & $8(1.8 \%)$ & $8(1.8 \%)$ & $1.02(0.38$ to 2.71$)$ & 0.97 \\
\hline Revascularisation: & $13(3.0 \%)$ & $17(3.9 \%)$ & $0.87(0.42$ to 1.83$)$ & 0.72 \\
\hline Urgent & $8(1.8 \%)$ & $13(3.0 \%)$ & 0.83 (0.34 to 1.99$)$ & 0.67 \\
\hline Target lesion & $4(0.9 \%)$ & $4(0.9 \%)$ & $1.02(0.25$ to 4.06$)$ & 0.98 \\
\hline Target vessel, non-target lesion & $2(0.5 \%)$ & $5(1.1 \%)$ & 0.40 (0.08 to 2.08$)$ & 0.28 \\
\hline Non-target vessel & $6(1.4 \%)$ & $10(2.3 \%)$ & 0.76 (0.26 to 2.18$)$ & 0.61 \\
\hline Stent thrombosis & $3(0.7 \%)$ & $4(0.9 \%)$ & 0.76 (0.17 to 3.39$)$ & 0.72 \\
\hline Stroke & $3(0.7 \%)$ & $3(0.7 \%)$ & $1.02(0.21$ to 5.03$)$ & 0.99 \\
\hline Bleeding: & $3(0.7 \%)$ & $5(1.1 \%)$ & 0.61 (0.15 to 2.53$)$ & 0.49 \\
\hline Thrombolysis in myocardial infarction major & $1(0.2 \%)$ & $2(0.5 \%)$ & $0.51(0.05$ to 5.57$)$ & 0.58 \\
\hline BARC type 3 & $2(0.5 \%)$ & $4(0.9 \%)$ & 0.50 (0.09 to 2.75$)$ & 0.43 \\
\hline Target lesion failureł & $5(1.2 \%)$ & $8(1.8 \%)$ & $0.63(0.21$ to 1.93$)$ & 0.42 \\
\hline Hospital stay: & $33(7.6 \%)$ & $38(8.7 \%)$ & $0.92(0.58$ to 1.48$)$ & 0.74 \\
\hline Cardiac & $26(6.0 \%)$ & $33(7.6 \%)$ & $0.84(0.50$ to 1.42$)$ & 0.52 \\
\hline Chest pain & $11(2.5 \%)$ & $13(3.0 \%)$ & $0.93(0.41$ to 2.10$)$ & 0.85 \\
\hline \multicolumn{5}{|c|}{$\begin{array}{l}\text { *All cause mortality, any myocardial infarction, any revascularization, stroke, and thrombolysis in myocardial infarction major bleeding (net adverse clinica } \\
\text { events). } \\
\text { †All cause mortality, any myocardial infarction, stent thrombosis, stroke, and thrombolysis in myocardial infarction major bleeding. } \\
\text { ‡Cardiac death, target lesion revascularization, or target lesion myocardial infarction. } \\
\text { BARC=Bleeding Academic Research Consortium }\end{array}$} \\
\hline
\end{tabular}

dual antiplatelet therapy (DAPT) after primary percutaneous coronary intervention (PCI) for STelevation myocardial infarction (STEMI). The trial showed that limiting DAPT to six months in patients that were event-free resulted in a non-inferior clinical outcome, as assessed by the patient-oriented

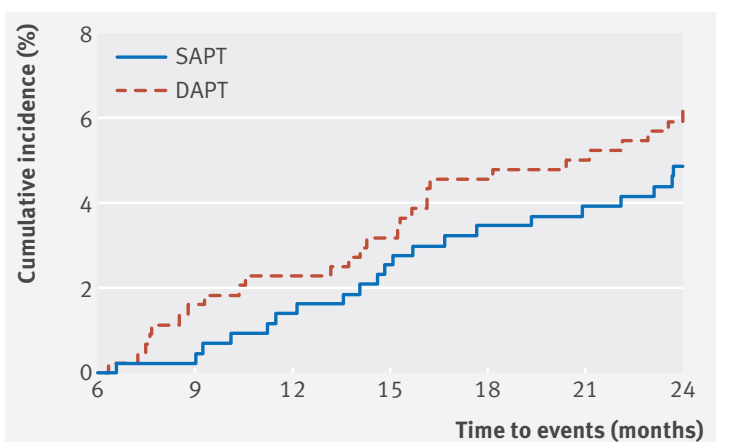

No at risk

SAPT

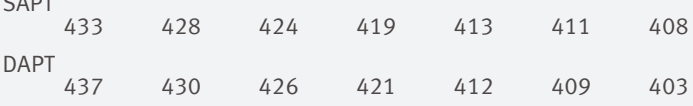

SAPT versus DAPT: $4.8 \%$ versus $6.6 \%$

Hazard ratio $0.73(95 \% \mathrm{Cl} 0.41$ to 1.27$)$

$\mathrm{H}=0.26$
$\mathrm{P}=0.004 \mathrm{fo}$

$\mathrm{P}=0.004$ for non-inferiority

Fig 2 | Cumulative incidence of the primary composite endpoint. The number at risk was defined as the number of patients who had not had the event of interest and who were available for subsequent follow-up composite clinical endpoint of safety, efficacy, and bleeding, versus the currently recommended regimen of 12 months DAPT. Furthermore, no noticeable difference was observed with regard to the major secondary composite endpoint of safety and bleeding. In addition, neither statistically significant nor meaningful numerical differences were observed for the components of the composite endpoints: all cause mortality, any myocardial infarction, any revascularisation, stent thrombosis, stroke, or thrombolysis in myocardial infarction major bleeding. The primary endpoint, as well as all its individual components showed low event occurrence in both treatment arms, suggesting that patients that were event-free at six months remain at a low risk for further events, irrespective of whether DAPT is continued or not. Our findings are in line with those of other randomised studies which compared six versus 12 months of DAPT. ${ }^{22-24}$ Our findings also support the low number of events seen in patients with STEMI after PCI with second generation drug-eluting stents. Another interesting finding which can be observed from the Kaplan-Meier curves is that stopping DAPT (both in the six and 12 months arms) was not associated with a rebound effect on primary endpoint events. This may suggest that DAPT may have no further protective effect beyond these points in time, however, further data are needed to explore specifically the potential rebound effect of DAPT discontinuation at different time points. 
Table | 3 Non-inferiority of SAPT versus DAPT calculated across different thresholds of the hazard ratio

\begin{tabular}{llll} 
Hazard ratio threshold & Wald $\chi^{2}$ & DF & $\operatorname{Pr}>\chi^{2}$ \\
1.1 & 2.1037 & 1 & 0.1469 \\
\hline 1.2 & 3.0768 & 1 & 0.0794 \\
\hline 1.3 & 4.1349 & 1 & 0.0420 \\
\hline 1.4 & 5.2536 & 1 & 0.0219 \\
\hline 1.5 & 6.4154 & 1 & 0.0113 \\
\hline 1.66 & 8.3323 & 1 & 0.0039
\end{tabular}

Wald statistic was used to test the estimated parameter against a hypothetical population value. The Wald test was computed as the squared difference of the parameter estimate (B) against the hypothetical value divided by the standard error estimate. In a test for the global null value divided by the standard error estimate. In a test for the global null
hypothesis the parameter estimate was tested against a value of $0(\mathrm{HR}=1)$. The other tests tested whether the estimated parameter differs from 0.095 for a hazard ratio of 1.1, from 0.182 for a hazard ratio of 1.2 etc. The Wald test was performed using Proc PHREG in SAS 9.4.

The low event rates after primary PCI with the Resolute Integrity second generation zotarolimuseluting stent might be attributed to the improved design of this device, as compared with first generation drug-eluting stents. Indeed, thinner stent struts favour a better and homogeneous endothelial strut coverage as compared with the thicker stainless steel struts of the first generation drug-eluting stents, ${ }^{25}$ and drugeluting stents with thin struts have shown a low risk of adverse cardiovascular events in patients with a variety of clinical syndromes. ${ }^{26}$ The Resolute Integrity second generation zotarolimus-eluting stent uses a biocompatible durable polymer that enables longer drug elution and has shown to affect the amount of neointima compared with the previous zotarolimuseluting platform. ${ }^{27}$ Moreover the almost complete neointimal coverage within three months after the implantation of Resolute Integrity second generation zotarolimus-eluting stent, as observed by optimal coherence tomographic studies, supports a shorter DAPT period. ${ }^{28} 29$

On the other hand, it is well known that patients with STEMI may have multiple complex coronary plaques, associated with a generally increased risk of adverse cardiovascular events, ${ }^{30}$ as well as other vulnerable plaques with traits of instability elsewhere in their coronary tree. ${ }^{31}$ Nevertheless, remaining complex "non-culprit" lesions are now generally treated after or even during the primary PCI. Regarding the remaining non-significant lesions with traits of "vulnerability," the current understanding is that many of these characteristics may be short lived, as in most cases these plaques progress through a process of asymptomatic plaque rupture and healing to more stable atherosclerotic lesions while other plaques remain unchanged. $^{32}$ Therefore, based on this understanding of atherosclerosis progression, it is much more likely that these plaques may remain clinically silent or manifest as stable rather than an acute coronary syndrome. As such, while DAPT as secondary prevention may reduce cardiovascular events originating from atherosclerosis progression elsewhere in the coronary tree, ${ }^{33}{ }^{34}$ these events are rare and the benefits of the reduction of ischaemic events may not outweigh the increase in the risk of bleeding, related to prolonged DAPT, as recently shown in the Pegasus and DAPT trials. ${ }^{33}{ }^{35}$ Major bleeding is an adverse event that is strongly related to mortality. ${ }^{36}$ Recent studies have even shown that bleeding is a stronger predictor of non-cardiovascular mortality than thromboembolic and ischaemic events. ${ }^{36} 37$ Indeed, prolonged DAPT did not impact mortality in the Pegasus and OPTIDUAL trials, ${ }^{33} 38$ but it was associated with a higher all cause mortality in the DAPT trial. ${ }^{35}$ Based on this evidence and considering that atherosclerosis is a lifelong disease, the role of DAPT in secondary prevention remains questionable. While DAPT does not have a major impact on the progression of atherosclerosis which in a large extent is based on rupturing and healing plaques, it might have some impact on its clinical presentation. In other words: the use of DAPT may result in more patients presenting with stable angina pectoris rather than acute coronary syndromes. ${ }^{39}$ As this could influence the need for ischemia-driven revascularization during the treatment period, we incorporated the endpoint "any revascularisation" into the primary clinical endpoint of our trial.

Finally, given the potential trade-off between ischaemic versus bleeding risks for any given duration of DAPT, the use of scores might prove useful to tailor DAPT. ${ }^{11}$ However, while the DAPT score estimates ischaemic and bleeding risks for prolonged DAPT and the PRECISE DAPT and PARIS risk scores predict bleeding during DAPT supporting clinical decision making for treatment duration, none of these risk prediction models have been prospectively tested in the setting of a randomised controlled trial, and even less in patients with STEMI. ${ }^{40-43}$ Therefore, the value of the risk scores in improving patient outcomes remains unknown.

\section{Limitations of the study}

This study has limitations. The primary endpoint is a combined endpoint of major adverse cardiac and cerebrovascular events and bleeding. While this endpoint might not give clear insights for each of these components, considering the bivalent impact of DAPT so much in ischaemic as well as bleeding outcomes we believe this endpoint gives better insights to the overall patient outcome. Moreover, individual clinical endpoints were not in opposite directions when comparing DAPT versus SAPT. Excluding the patients with events in the 6 months does indeed introduce a bias of patients at low risk, however, rather than being a selection bias, it reflects more the trial design.

In this trial, the rate of patient enrolment was not high. This may reflect the absence of previous data in this setting and the difficulty of obtaining patient consent to participate in the trial, this was also reflected by the high number of withdrawals at six months.

The lower than estimated occurrence of events in both arms, may be perceived as another limitation of this trial, but reflects the design of this trial: only patients that were event-free at six months were randomised, which may have excluded a certain proportion 
of patients at higher risk from randomisation. Furthermore, the observed event occurrence is in line with previous trials performed with modern drugeluting stents. ${ }^{2344}$ To avoid the biases that the low event occurrence could introduce to a non-inferiority design based on a fixed percentage of the expected event, we chose a non-inferiority design based on hazard ratios. In this model, lower than expected event occurrence would enlarge the confidence intervals and therefore challenge the non-inferiority, however, this was not the case in our trial as the hazard ratio was 0.73 and the upper confidence interval was 1.27 , much lower than the prespecified margin of 1.66. Considering that our endpoint did combine ischaemic and bleeding events, we were expecting a benefit for SAPT, ${ }^{23} 333544$ and therefore we could have chosen a more conservative non-inferiority margin than 1.66 , however, taking into account a possible chance finding (a benefit in favour of DAPT) we chose a wider margin. It has to be noted that the large non-inferiority margin did not influence the observed non-inferiority as a post hoc analysis showed that the trial would have proved non-inferior even for a much more conservative noninferiority margin of 1.3 (see table 3).

Another limitation is that fewer patients than predicted were randomised at six months follow-up. The design of the trial in which only patients that were event-free at six months could be randomised contributed to this issue; other reasons were the higher than expected number of withdrawals and the treatment of non-culprit coronary lesions outside the prespecified accepted time window for staged PCI procedures, which we could not predict when designing the trial. Indeed, the last reason also explains in part why the number of non-culprit coronarylesion treatments in this trial appears low. However, a post hoc analysis showed that the number of actual versus planned patients that were randomised had only a minimal influence in the trial power reducing it by only $3 \%$.

The time from the onset of pain until revascularisation as well as door to balloon time were not recorded in this trial, however, considering that the randomisation occurred only at six months in patients that were eventfree, such information would not importantly impact the trial outcomes.

Per protocol, the choice of the P2Y12 inhibitor prescribed was at the operators' discretion reflecting the guidelines when this trial was designed. As can be observed in the baseline table, the different P2Y12 inhibitors were similarly distributed between treatment groups. Different P2Y12 inhibitors have different outcomes in safety endpoints or bleeding ${ }^{45}$ however, potential differences in outcomes between patients treated with different P2Y12 inhibitors can only be appreciated in studies with much larger population sizes than our present trial. Furthermore, because we used a composite endpoint, any possible advantage of prasugrel or ticagrelor in ischaemic outcomes is counterbalanced from the bleeding outcomes. We do not expect that clopidogrel introduced any bias in our results, and if so it would rather underestimate the benefit of SAPT. Moreover, according to guidelines when neither prasugrel or ticagrelor are available, or if they are contraindicated, clopidogrel should be prescribed. Thus the presence of clopidogrel in our trial may still be of importance for those patients that are treated with clopidogrel, especially in countries which, for economic reasons, cannot afford the cost of new P2Y12 inhibitors.

The Resolute Integrity second generation zotarolimus-eluting stent was used in $93 \%$ of the patients and thus further studies with other second generation drug-eluting stents will be required to establish the extension of this finding. Finally, although cardiogenic shock was not an exclusion criteria for enrolment, patients with overt cardiogenic shock were not enrolled because they were not able to provide informed consent and therefore, the results of this trial cannot apply to these patients as well as for patients with lesions requiring left main stenting who were excluded from the trial.

\section{Conclusions}

In patients that are event-free six months after primary PCI with second generation drug-eluting stents, six months of DAPT was associated with outcomes not inferior to those observed after 12 months of DAPT. While larger trials have shown that longer duration of DAPT regimens might be associated with favourable ischaemic outcomes, this trial for the first time shows that a shorter DAPT duration is also feasible and safely applicable if clinically required even in patients with STEMI, setting the stage for further dedicated research on DAPT duration in this category of patients that are at high risk.

\section{AUTHOR AFFILIATIONS}

${ }^{1}$ Isala Hartcentrum, Isala Klinieken, Zwolle, Netherlands

${ }^{2}$ Cardiovascular Department, University of Trieste, Trieste, Italy

${ }^{3}$ Maasstad Ziekenhuis, Rotterdam, Netherlands

${ }^{4}$ American Heart of Poland, Ustroń, Poland

${ }^{5}$ Medical University of Silesia, Katowice, Poland

${ }^{6}$ Thoraxcenter, Erasmus Medisch Centrum, Rotterdam, Netherlands

${ }^{7}$ University of Twente, Enschede, Netherlands

${ }^{8}$ American Heart of Poland, Chrzanów, Poland

${ }^{9}$ Haga Hospital, The Hague, Netherlands

${ }^{10}$ Zuyderland Medical Centre, Heerlen, Netherlands

${ }^{11}$ Department of Cardiology, Oslo Academic University, Oslo, Norway

${ }^{12}$ Department of Cardiology, University \& Hospital, Fribourg, Switzerland

${ }^{13}$ Department of Cardiology, Amphia Hospital, Breda, Netherlands

${ }^{14}$ Department of Cardiology, Radboud University Medical Centre, Nijmegen, Netherlands

${ }^{15}$ Sahlgrenska Academy, University of Gothenburg, and Nordic School of Public Health, Gothenburg, Sweden

${ }^{16}$ Heart Centre, Academic Medical Centre, University of Amsterdam, Amsterdam, Netherlands

We thank statisticians from University of Sahlgrenska, Gothenburg, Sweeden; University of Amsterdam, Amsterdam, Netherlands; and Diagram BV (CRO) for performing the statistical design and analysis.

Contributors: EK conceived and designed the study. HW performed the power calculation. RD performed the statistical analysis. EK and EF 
prepared the first draft of the manuscript. All other authors acquired the data, critically revised the manuscript, and approved the final manuscript. All authors had full access to the data in the study and can take responsibility for the integrity of the data and the accuracy of the data analysis. EK is the guarantor.

Funding: The trial was sponsored form the Maasstad Cardiovascular Research Rotterdam, The Netherlands and from an unrestricted research grant from Medtronic.

Competing interests: All authors have completed the ICMJE uniform disclosure form at www.icmje.org/coi disclosure.pdf and declare: no support from any organisation for the submitted work other than those listed above; no other financial relationships with organisations that might have an interest in the submitted work in the previous three years; no other relationships or activities that could appear to have influenced the submitted work.

Ethical approval: This study was conducted in accordance with the Declaration of Helsinki and was approved by the local research ethics committee.

Data sharing: The dataset is available on written request to the corresponding author.

Transparency: The manuscript's guarantor (EK) affirms that the manuscript is an honest, accurate, and transparent account of the study being reported; that no important aspects of the study have been omitted; and that any discrepancies from the study as planned and registered have been explained.

This is an Open Access article distributed in accordance with the Creative Commons Attribution Non Commercial (CC BY-NC 4.0) license, which permits others to distribute, remix, adapt, build upon this work non-commercially, and license their derivative works on different terms, provided the original work is properly cited and the use is noncommercial. See: http://creativecommons.org/licenses/by-nc/4.0/.

1 Sigwart U, Puel J, Mirkovitch V, Joffre F, Kappenberger L. Intravascular stents to prevent occlusion and restenosis after transluminal angioplasty. N Engl/ Med 1987:316:701-6. doi:10.1056/ NEIM198703193161201

2 Levine GN, Bates ER, Blankenship JC, et al. 2011 ACCF/AHA/ SCAI Guideline for Percutaneous Coronary Intervention: a report of the American College of Cardiology Foundation/American Heart Association Task Force on Practice Guidelines and the Society for Cardiovascular Angiography and Interventions. Circulation 2011;124:e574-651

doi:10.1161/CIR.0b013e31823ba622

3 Serruys PW. FDA panel, 7 and 8 December 2006 - The impact on our practice and research. Eurolntervention 2007; 2:405-7. https://www.ncbi.nlm.nih.gov/pubmed/19755275.

4 Palmerini T, Biondi-Zoccai G, Della Riva D, et al. Stent thrombosis with drug-eluting and bare-metal stents: evidence from a comprehensive network meta-analysis. Lancet 2012;379:1393-402.

doi:10.1016/S0140-6736(12)60324-9

5 Kedhi E, Stone GW, Kereiakes DJ, et al. Stent thrombosis: insights on outcomes, predictors and impact of dual antiplatelet therapy interruption from the SPIRIT II, SPIRIT III, SPIRIT IV and COMPARE trials. Eurolntervention 2012;8:599-606. doi:10.4244/EIJV8I5A92

6 Kedhi E, Gomes M, Joesoef KS, et al. Everolimus-eluting stents and paclitaxel-eluting stents in patients presenting with myocardial infarction: insights from the two-year results of the COMPARE prospective randomised controlled trial. Eurolntervention 2012:7:1376-85 doi:10.4244/EIJV7I12A217

7 Généreux P, Rutledge DR, Palmerini T, et al. Stent Thrombosis and Dual Antiplatelet Therapy Interruption With Everolimus-Eluting Stents: Insights From the Xience V Coronary Stent System Trials. Circ Cardiovasc Interv 2015;8:e001362. doi:10.1161/CIRCINTERVENTIONS.114.001362

8 Giustino G, Baber U, Sartori S, et al. Duration of dual antiplatelet therapy after drug-eluting stent implantation: a systematic review and meta-analysis of randomized controlled trials. / Am Coll Cardiol 2015;65:1298-310. doi:10.1016/j.jacc.2015.01.039

9 Palmerini T, Sangiorgi D, Valgimigli M, et al. Short- versus long-term dual antiplatelet therapy after drug-eluting stent implantation: an individual patient data pairwise and network meta-analysis. J Am Coll Cardiol 2015;65:1092-102. doi:10.1016/j.jacc.2014.12.046

10 Windecker S, Kolh P, Alfonso F, et al, Authors/Task Force members. 2014 ESC/EACTS Guidelines on myocardial revascularization: The Task Force on Myocardial Revascularization of the European Society of Cardiology (ESC) and the European Association for Cardio-Thoracic Surgery (EACTS)Developed with the special contribution of the European Association of Percutaneous Cardiovascular
Interventions (EAPCI). Eur Heart/ 2014;35:2541-619. doi:10.1093/eurheartj/ehu278

11 Valgimigli M, Bueno H, Byrne RA, et al. [2017 ESC focused update on dual antiplatelet therapy in coronary artery disease developed in collaboration with EACTS]. Kardio Pol 2017;75:1217-99. doi:10.5603/KP.2017.0224

12 Steinhubl SR, Berger PB, Mann JT3rd, et al, CREDO Investigators. Clopidogrel for the Reduction of Events During Observation. Early and sustained dual oral antiplatelet therapy following percutaneous coronary intervention: a randomized controlled trial. JAMA 2002;288:2411-20. https://www.ncbi.nlm.nih.gov/ pubmed/12435254. doi:10.1001/jama.288.19.2411

13 Mehta SR, Yusuf S, Peters RI, et al. Effects of pretreatment with clopidogrel and aspirin followed by long-term therapy in patients undergoing percutaneous coronary intervention: the PCI-CURE study. Lancet 2001:358:527-33. https://www.ncbi.nlm.nih.gov/ pubmed/11520521.

14 Palmerini T, Benedetto U, Bacchi-Reggiani L, et al. Mortality in patients treated with extended duration dual antiplatelet therapy after drug-eluting stent implantation: a pairwise and Bayesian network meta-analysis of randomised trials. Lancet 2015:385: 2371-82. doi:10.1016/S0140-6736(15)60263-X

15 Kedhi E, Fabris E, van der Ent M, et al. A prospective, randomized open-label trial of 6 -month versus 12 -month dual antiplatelet therapy after drug-eluting stent implantation in ST-elevation myocardial infarction: Rationale and design of the "DAPT-STEMI trial". Am Heart / 2017;188:11-7. doi:10.1016/j.ahj.2017.02.018

16 Cutlip DE, Windecker S, Mehran R, et al, Academic Research Consortium. Clinical end points in coronary stent trials: a case for standardized definitions. Circulation 2007:115:2344-51. doi:10.1161/CIRCULATIONAHA.106.685313

17 Chesebro JH, Knatterud G, Roberts R, et al. Thrombolysis in Myocardial Infarction (TIMI) Trial, Phase I: A comparison between intravenous tissue plasminogen activator and intravenous streptokinase. Clinical findings through hospital discharge. Circulation 1987;76:142-54. https://www.ncbi.nlm.nih.gov/ pubmed/3109764. doi:10.1161/01.CIR.76.1.142

18 Patel MR, Mahaffey KW, Garg J, et al, ROCKET AF Investigators. Rivaroxaban versus warfarin in nonvalvular atrial fibrillation. $N$ Engl J Med 2011;365:883-91. doi:10.1056/NEJMoa1009638

19 Connolly SJ, Ezekowitz MD, Yusuf S, et al, RE-LY Steering Committee and Investigators. Dabigatran versus warfarin in patients with atrial fibrillation. N Engl I Med 2009;361:1139-51. doi:10.1056/NEJMoa090556

20 Stone GW, Teirstein PS, Meredith IT, et al, PLATINUM Trial Investigators. A prospective, randomized evaluation of a novel everolimus-eluting coronary stent: the PLATINUM (a Prospective, Randomized, Multicenter Trial to Assess an Everolimus-Eluting Coronary Stent System [PROMUSUS Element] for the Treatment of Up to Two de Novo Coronary Artery Lesions) trial. J Am Coll Cardiol 2011:57:1700-8 doi:10.1016/j.jacc.2011.02.016

21 Albers GW, Diener H-C, Frison L, et al, SPORTIF Executive Steering Committee for the SPORTIF V Investigators. Ximelagatran vs warfarin for stroke prevention in patients with nonvalvular atrial fibrillation: a randomized trial. IAMA 2005:293:690-8. doi:10.1001/jama.293.6.690

22 Hong S-J, Shin D-H, Kim J-S, et al, IVUSUS-XPL Investigators. 6-Month Versus 12-Month Dual-Antiplatelet Therapy Following Long Everolimus-Eluting Stent Implantation: The IVUSUS-XPL Randomized Clinical Trial. JACC CardiovasC Interv 2016;9:1438-46. doi:10.1016/j.jcin.2016.04.036

23 Han Y, Xu B, Xu K, et al. Six Versus 12 Months of Dual Antiplatelet Therapy After Implantation of Biodegradable Polymer Sirolimus-Eluting Stent: Randomized Substudy of the I-LOVE-IT 2 Trial. Circ Cardiovasc Interv 2016:9:e003145. doi:10.1161/CIRCINTERVENTIONS.115.003145

24 Colombo A, Chieffo A, Frasheri A, et al. Second-generation drug-eluting stent implantation followed by 6 - versus 12-month dual antiplatelet therapy: the SECURITY randomized clinical trial. J Am Coll Cardiol 2014;64:2086-97. doi:10.1016/j.jacc.2014.09.008

25 Iannaccone M. D’Ascenzo F. Templin C, et al. Optical coherence tomography evaluation of intermediate-term healing of different stent types: systemic review and meta-analysis. Eur Heart J Cardiovasc Imaging 2017;18:159-66. doi:10.1093/ehjci/jew070

26 von Birgelen C, Kok MM, van der Heijden LC, et al. Very thin strut biodegradable polymer everolimus-eluting and sirolimus-eluting stents versus durable polymer zotarolimus-eluting stents in allcomers with coronary artery disease (BIO-RESORT): a three-arm, randomised, non-inferiority trial. Lancet 2016:388:2607-17. doi:10.1016/S0140-6736(16)31920-1

27 Waseda K, Ako J, Yamasaki M, et al. Impact of polymer formulations on neointimal proliferation after zotarolimus-eluting 
stent with different polymers: insights from the RESOLUTE trial. Circ Cardiovasc Interv 2011;4:248-55 doi:10.1161/CIRCINTERVENTIONS.110.957548

28 Hashikata T, Tojo T, Namba S, et al. Neointimal coverage of zotarolimus-eluting stent at 1, 2, and 3 months' follow-up: an optical coherence tomography study. Heart Vessels 2016;31:206-11 doi:10.1007/s00380-014-0598-0

29 Kim S-J, Lee H, Cho J-M, et al. Comparison of zotarolimuseluting stent and everolimus-eluting stent for vascular healing response: serial 3-month and 12-month optical coherence tomography study. Coron Artery Dis 2013;24:431-9. doi:10.1097/MCA.0b013e328362b2e7

30 Goldstein JA, Demetriou D, Grines CL, Pica M, Shoukfeh M, O'Neill WW. Multiple complex coronary plaques in patients with acute myocardial infarction. N Engl J Med 2000;343:915-22. doi:10.1056/NEJM200009283431303

31 Kubo T, Imanishi T, Kashiwagi M, et al. Multiple coronary lesion instability in patients with acute myocardial infarction as determined by optical coherence tomography. Am J Cardiol 2010;105:318-22. doi:10.1016/j.amjcard.2009.09.032

32 Kubo T, Maehara A, Mintz GS, et al. The dynamic nature of coronary artery lesion morphology assessed by serial virtual histology intravascular ultrasound tissue characterization. J Am Coll Cardiol 2010;55:1590-7. doi:10.1016/j.jacc.2009.07.078

33 Bonaca MP, Bhatt DL, Cohen M, et al, PEGASUSUS-TIMI 54 Steering Committee and Investigators. Long-term use of ticagrelor in patients with prior myocardial infarction. N Engl I Med 2015;372:1791-800. doi:10.1056/NEJMoa1500857

34 Bhatt DL, Fox KAA, Hacke W, et al, CHARISMA Investigators. Clopidogrel and aspirin versus aspirin alone for the prevention of atherothrombotic events. N Engl J Med 2006;354:1706-17. doi:10.1056/NEJMoa060989

35 Mauri L, Kereiakes DJ, Yeh RW, et al, DAPT Study Investigators. Twelve or 30 months of dual antiplatelet therapy after drug-eluting stents. N Engl I Med 2014;371:2155-66. doi:10.1056/NEJMoa1409312

36 Généreux P, Giustino G, Witzenbichler B, et al. Incidence, Predictors, and Impact of Post-Discharge Bleeding After Percutaneous Coronary Intervention. I Am Coll Cardiol 2015:66:1036-45. doi:10.1016/j.jacc.2015.06.1323

37 Capodanno D, Gargiulo G, Buccheri S, Giacoppo D, Capranzano P, Tamburino C. Meta-Analyses of Dual Antiplatelet Therapy Following Drug-Eluting Stent Implantation: Do Bleeding and Stent Thrombosis Weigh Similar on Mortality? J Am Coll Cardiol 2015;66:1639-40. doi:10.1016/j.jacc.2015.05.085

38 Helft G, Steg PG, Le Feuvre C, et al, OPTImal DUAL Antiplatelet Therapy Trial Investigators. Stopping or continuing clopidogrel
12 months after drug-eluting stent placement: the OPTIDUAL randomized trial. Eur Heart J 2016;37:365-74. doi:10.1093/ eurheartj/ehv481

39 Rittersma SZH, van der Wal AC, Koch KT, et al. Plaque instability frequently occurs days or weeks before occlusive coronary thrombosis: a pathological thrombectomy study in primary percutaneous coronary intervention. Circulation 2005;111:1160-5. doi:10.1161/01.CIR.0000157141.00778.AC

40 Yeh RW, Secemsky EA, Kereiakes DJ, et al, DAPT Study Investigators. Development and Validation of a Prediction Rule for Benefit and Harm of Dual Antiplatelet Therapy Beyond 1 Year After Percutaneous Coronary Intervention. JAMA 2016;315:1735-49. doi:10.1001/jama.2016.3775

41 Costa F, van Klaveren D, James S, et al, PRECISE-DAPT Study Investigators. Derivation and validation of the predicting bleeding complications in patients undergoing stent implantation and subsequent dual antiplatelet therapy (PRECISE-DAPT) score: a pooled analysis of individual-patient datasets from clinical trials. Lancet 2017;389:1025-34 doi:10.1016/S0140-6736(17)30397-5

42 Mehran R, Baber U, Steg PG, et al. Cessation of dual antiplatelet treatment and cardiac events after percutaneous coronary intervention (PARIS): 2 year results from a prospective observational study. Lancet 2013;382:1714-22. doi:10.1016/S0140-6736(13)61720-1

43 Baber U, Mehran R, Giustino G, et al. Coronary Thrombosis and Major Bleeding After PCI With Drug-Eluting Stents: Risk Scores From PARIS. J Am Coll Cardiol 2016;67:2224-34 doi:10.1016/j.jacc.2016.02.064

44 Schulz-Schüpke S, Byrne RA, Ten Berg JM, et al, Intracoronary Stenting and Antithrombotic Regimen: Safety And EFficacy of 6 Months Dual Antiplatelet Therapy After Drug-Eluting Stenting (ISAR-SAFE) Trial Investigators. ISAR-SAFE: a randomized, doubleblind, placebo-controlled trial of 6 vs. 12 months of clopidogrel therapy after drug-eluting stenting. Eur Heart / 2015;36:1252-63. doi:10.1093/eurheartj/ehu523

45 Zocca P, van der Heijden LC, Kok MM, et al.Clopidogrel or ticagrelor in acute coronary syndrome patients treated with newer-generation drug-eluting stents: CHANGE DAPT. Eurolntervention 2017;13:116876. doi:10.4244/eij-d-17-00634

Supplementarymaterials: Definitions, supplementary figures e1-e3, and supplementary table e1 